\title{
Management of blind-end subglottic stenosis following SARS-CoV-2 infection: a case report
}

\author{
Ernest G. Chan^, Eric J. Hyzny, Masashi Furukawa, James D. Luketich, Pablo G. Sanchez \\ Department of Cardiothoracic Surgery, University of Pittsburgh Medical Center, Pittsburgh, PA, USA \\ Correspondence to: Pablo G. Sanchez, MD, PhD, Vice Chair of Benign Lung Diseases, Surgical Director of Lung Transplant and ECMO, Director of \\ Ex vivo Lung Perfusion, Director of Lung Transplant Research. Department of Cardiothoracic Surgery, University of Pittsburgh, Pittsburgh, PA, \\ USA. Email: sanchezpg@upmc.edu.
}

Background: Reports identify rates of prolonged intubation as high as $28 \%$ in patients who are hospitalized for worsening respiratory status due the SARS-CoV-2 infection. This has placed a toll on healthcare systems around the world. However, we believe we are only seeing the beginnings of complications associated with the COVID-19 pandemic. Subglottic tracheal stenosis is a known complication of prolonged intubation and may therefore be on the rise in the wake of the current pandemic. The European Laryngology Society created the Laryngotracheal Stenosis Committee to alert the international medical community of the rise in airway complications associated with long-term intubation and high rates of tracheostomy seen in the recent months during the pandemic. Optimal surgical management of the unique features of subglottic stenosis following COVID-19 disease, especially in severely deconditioned patients, has yet to be reported.

Case Description: We report the surgical management of blind-end Myer-Cotton Grade IV subglottic stenoses in two patients who required prolonged mechanical ventilatory support for respiratory failure resulting from the SARS-CoV-2 infection with a two stage minimally invasive recanalization strategy. Patients underwent two-step minimally invasive process for recanalization. The first step is to re-establish a patent tracheal lumen under direct visualization utilizing both a rigid bronchoscope from proximally as well as a flexible bronchoscope distal to the stenosis from the tracheostomy stoma. Once the tracheal lumen is reestablished, proper dilation of the airway and hemostasis is achieved in standard fashion. Both patients have had roughly 6 months of follow-up and have tolerated their silicone T-tubes capped at all times. Neither patient currently require any oxygen supplementation and continue to phonate well. While they are not at their baseline in terms of physical activity, they are continuing their rehabilitation process.

Conclusions: While the definitive treatment continues to be surgical resection, the endoscopic approach to re-establishing the tracheal lumen is a safe and effective method with little to no morbidity and mortality. This will allow for uninhibited rehabilitation following prolonged mechanical ventilatory support and hospital stay following severe COVID-19 infection.

Keywords: Subglottic stenosis; COVID-19; prolonged mechanical ventilation; case series; SARS-CoV-2 infection

Received: 19 August 2021; Accepted: 12 January 2022; Published: 30 April 2022.

doi: $10.21037 /$ shc-21-23

View this article at: https://dx.doi.org/10.21037/shc-21-23

\section{Introduction}

Prolonged intubation and tracheostomy placement are associated with an increased risk of airway complications including subglottic stenosis with rates as high as $20 \%$ historically (1-3). Due to improved equipment and patient management, contemporary rates of subglottic stenosis are much lower with rates as low as $6 \%$ and $0.6 \%$ in

\footnotetext{
^ ORCID: 0000-0001-9849-6371.
} 

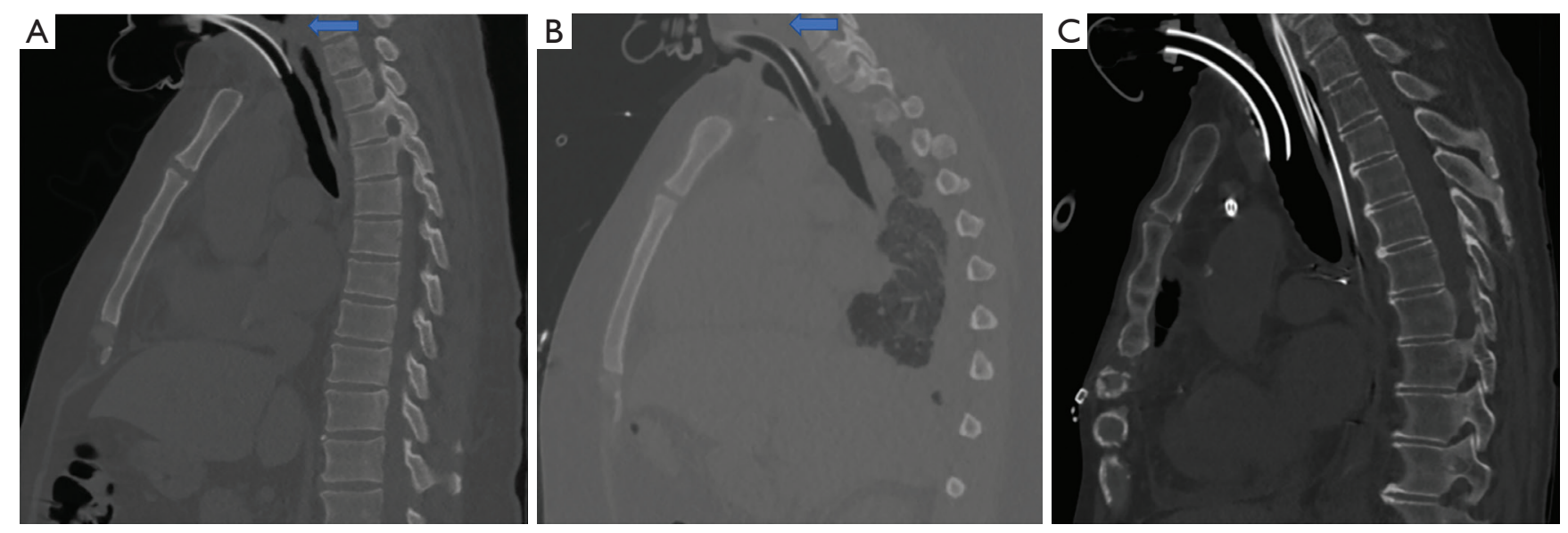

Figure 1 CT scans identifying the formation of a pseudomembrane (blue arrow) above the tracheostomy tube in case 1 (A) and case 2 (B); (C) is provided as a reference regarding how a tracheostomy tube sits in the trachea without any subglottic stenosis. CT, computed tomography.

patients who underwent intubation and tracheostomy respectively (4-7). Patients requiring prolonged intubation or tracheostomy at the highest risk of airway stenosis include those with diabetes and obesity (8). Similarly, patients diagnosed with severe COVID-19 infection share similar comorbidities (9). Because of the recent ongoing pandemic, the European Laryngology Society created the Laryngotracheal Stenosis Committee to alert the international medical community of the rise in airway complications associated with long-term intubation and high rates of tracheostomy seen in the recent months (10). As we are improving our ability to treat SARS-CoV-2 infection, we are able to extubate more patients or offer a tracheostomy to progress them to rehabilitation to minimize the risk of laryngeal trauma. We report two cases of severe blind-end grade IV Cotton-Myer subglottic stenosis in patients who required prolonged intubation and tracheostomy placement following severe respiratory failure from COVID-19 (11). We present the following two cases in accordance with the CARE reporting checklist (available at https://shc.amegroups. com/article/view/10.21037/shc-21-23/rc).

\section{Case presentation}

\section{Case 1}

A 51-year-old obese African American male presented to the emergency room with worsening respiratory insufficiency after testing positive for the SARS-CoV-2 virus 3 days prior. He was urgently intubated but it quickly became clear that mechanical ventilation would not sufficiently oxygenate him and he was placed on venoveno extracorporeal membrane oxygenation (VV-ECMO). Despite maximizing VV-ECMO support, he was placed in the prone position for 16 hours a day for 14 days. In total, he required 35 days of VV-ECMO support. Once the patient showed signs of improvement from a respiratory standpoint, he underwent a percutaneous tracheostomy under direct bronchoscopic visualization from above the vocal cords to ensure the proper positioning.

Since being weaned from the ventilator, he was transitioned to a cuffless tracheostomy. While continually rehabilitating, the medical staff noticed the patient's inability to phonate. A computed tomography (CT) scan was obtained identifying an area of subglottic stenosis with a $2-3 \mathrm{~mm}$ pseudomembrane (Figure $1 A$ ). Once the patient was brought to the operating room with thoracic surgery, it was recognized that the patient had developed a grade IV Cotton-Myer subglottic stenosis roughly 5 millimeters distal to the vocal cords.

\section{Case 2}

A 35-year-old obese African American male with type II diabetic presented to an outside hospital with worsening respiratory status after testing positive for the SARS-CoV-2 virus. He was transferred to our hospital due to increasing oxygen requirements despite being proned. Once he arrived, he was placed on VV-ECMO. Overall, he required 33 days of VV-ECMO support. He was proned for 2 additional days and underwent a percutaneous tracheostomy under direct bronchoscopic visualization once his respiratory status was 

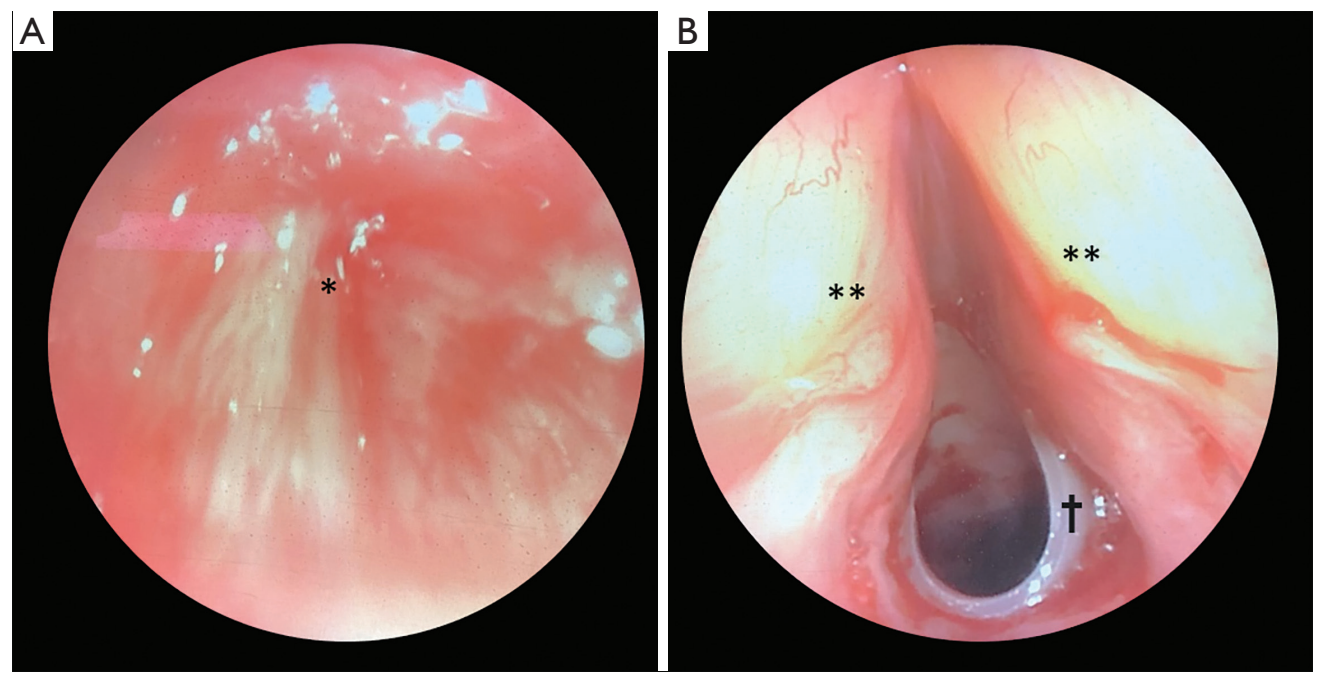

Figure 2 Direct visualization of the blind-end grade IV Myers-Cotton subglottic stenosis. (A) 5 mm below the vocal cords identified via flexible bronchoscopy $\left(^{*}\right)$; (B) a silicon T-tube $(\dagger)$ was placed after recanalization and dilation of the trachea with the proximal B limb sitting just below the vocal cords $\left({ }^{* *}\right)$.

improving.

In similar fashion to the first case, while rehabilitating, the medical team had noticed he was not tolerating the use of a Passy Muir Valve (PMV). A CT scan showed a subglottic stenosis which was confirmed to be a grade IV Cotton-Myer subglottic stenosis (2-3 mm pseudomembrane) roughly 5$6 \mathrm{~mm}$ distal to the vocal cords and above the tracheostomy site (Figure $1 B$ ). Figure $1 C$ is provided as a reference to demonstrate the positioning of an endotracheal (ET) tube in a patient with normal tracheal morphology.

\section{Ethical statement}

All procedures performed in this study were in accordance with the ethical standards of the institutional and/or national research committee(s) and with the Helsinki Declaration (as revised in 2013). Written informed consent was obtained from both patients for publication of this case report and accompanying images. A copy of the written consent is available for review by the editorial office of this journal. Due to the retrospective nature of this case series and since no patient identifiers have been provided in this report, our institutional review board (IRB) has granted exception from review.

\section{Minimally invasive management}

After the grade IV Cotton-Myer subglottic stenosis was identified in the operating room by bronchoscopy, once the patient was fully anesthetized, the tracheostomy was switched under direct visualization with a reinforced ET tube. A rigid bronchoscope was placed just distal to the vocal cords with the blind end of the subglottic stenosis directly perpendicular to the tip of the scope (Figure 2A). Once the patient was hyperoxygenated, the ET tube was removed and a flexible bronchoscope was placed into the tracheal stoma and positioned at the distal side of the subglottic stenosis. This positioning was identified via palpation from the proximal side through the rigid bronchoscope. Once the anatomy of the subglottic stenosis was clear, a sharp dissector was placed through the rigid bronchoscope and advanced through the subglottic stenotic membrane under direct visualization from both sides. Once recanalized, the tracheal was serially dilated with tracheal dilators to 40 French. The patient was then orally intubated with a 9-0 ET tube in order to keep the stenotic segment dilated. Dexamethasone was administered for the next few days.

After 3 to 4 days, the patient was brought back to the operating room to reassess the stenotic segment. Under general anesthesia, a small incision was made on the tracheostomy stoma to identify the trachea. A transversal cut of the proximal ring was made with an 11 blade in the midportion to easily advance a silicon T-tube. The proximal B limb was placed across the stenotic portion of the trachea with the tip just distally to the vocal cords (Figure $2 B$ ). After 
the procedure, once the patients were awake, they were able to immediately phonate in the operating room and was oxygenating well on nasal cannula.

\section{Long-term follow-up}

Both patients have had roughly 6 months of follow-up since the initial procedure. They have tolerated their silicone T-tubes capped at all times with intermittent suctioning when needed. Neither patient currently require any oxygen supplementation and continue to phonate well. While they are not at their baseline in terms of physical activity, they are continuing their rehabilitation process. Both patients have been brought back to the operating room every 6 to 8 weeks for T-tube exchanges and reevaluation of the stenotic segment of their trachea. While the stenotic portions have scarred down to a reasonable diameter, they continue to have signs of tracheomalacia and we have therefore maintained the use of their T-tubes.

\section{Discussion}

Tracheal stenosis following prolonged intubation is a morbid complication that is difficult to manage. In the latter part of the $20^{\text {th }}$ century, Dr. Cooper and Dr. Grillo found that the local breakdown of the tracheal cartilage and tissue lead to extensive fibrosis and contraction which ultimately resulted in tracheal stenosis (12). This was further reported in a prospective study by Pearson and colleagues when they bronchoscopically observed patients post-decannulation and found similar significant damage at the site of the cuff (13). These pioneers in the field attributed these findings to the rigid and noncompliant cuffs that often strangulated the tissue they were in contact with. Since the advent of highvolume low-pressure cuffs, the incidence of tracheal stenosis associated with prolonged ventilatory support has decreased significantly but still remains prevalent at around 11\% (3).

As more COVID-19 positive patients improve, experts from European Laryngology Society's Laryngotracheal Stenosis Committee have stressed the coming increase in airway complications because of mechanical ventilatory support. It is hypothesized that because patients with SARS-CoV-2 infection are associated with a prothrombotic and antifibrinolytic state as well as are treated with chronic systemic steroids, they may be most at risk for tracheal stenosis following mechanical ventilation (14). Others have suggested that the emotional and physical exhausted state of healthcare professional during the pandemic outbreak may have understandably compromised the care of some of these patients (15). Ultimately, the best option is to avoid the development of this issue with best practices outlined by this committee may be the most effective way in managing these patients.

Nonetheless, within the coming months to years, more of these patients will present to our practices worldwide. While less aggressive subglottic stenotic tracheal segments may be dilated and treated based on standard protocol, albeit rare, we believe a small percentage of patients will present with blind-end grade IV Cotton-Myer subglottic stenosis. In the two cases presented, our patients presented with inability to phonate and tolerate a PMV despite improving respiratory status. CT scans confirmed the development of tissue above the tracheostomy not present normally in a standard patient with a tracheostomy (Figure 1C). While it is unclear exactly when this occurred or what is the exact cause, this severe form of subglottic stenosis limited their recovery and rehabilitation. Furthermore, the inability to phonate and communicate negatively impacted their mental health.

Due to the detrimental and morbid nature these tracheal lesions, we recommend immediate treatment without delay. Because these patients were already so deconditioned from a prolonged 2-3-month hospital stay, there was no question they were not surgical candidates for a subglottic tracheal resection followed by a complex airway reconstruction. Therefore, we recommend treatment of this complex tracheal lesion with a two-step minimally invasive process. The first step is to re-establish a patent tracheal lumen which can be done under direct visualization utilizing both a rigid bronchoscope from above as well as a flexible bronchoscope from the tracheostomy stoma. The positioning of the neck with some hyperflexion is key to allow for the trachea to be in complete parallel with the rigid bronchoscope placed above. This will allow for palpation of the pseudo-membrane and identification of the correct trajectory prior to puncturing it. Once the tracheal lumen is re-established, proper dilation of the airway and hemostasis is achieved in standard fashion. The lumen is kept patent with a large ET tube to minimize further granulation.

We believe re-establishing the tracheal lumen and allowing for the maturation of the newly dilated stenotic portion with an ET tube along with steroid treatment minimizes chances of the pseudo-membrane reforming. Because these patients are not well suited for definitive treatment by surgical resection, we recommend the second 
step which is to remove a small portion of the upper cartilage in which the stenotic segment affects and to place a silicon T-tube. While the patient is rehabilitating, this will allow for proper hygiene, comfort, and phonation. Following T-tube placement, patients are brought back to the operating room for maintenance and airway reevaluation. We continue to follow these patients and will reassess their surgical candidacy moving forward.

In conclusion, subglottic tracheal stenosis is a known complication of prolonged intubation that may be on the rise in the wake of the recent COVID-19 pandemic. It may come in many forms ranging from a small segment to a fully compromised tracheal lumen. While the definitive treatment continues to be surgical resection, minimally invasive and endoscopic measures should be taken immediately to temporize the issue as it allows for the patient to continue the rehabilitation process uninhibited.

\section{Acknowledgments}

Funding: None.

\section{Footnote}

Reporting Checklist: The authors have completed the CARE reporting checklist. Available at https://shc.amegroups.com/ article/view/10.21037/shc-21-23/rc

Peer Review File: Available at https://shc.amegroups.com/ article/view/10.21037/shc-21-23/prf

Conflicts of Interest: All authors have completed the ICMJE uniform disclosure form (available at https://shc.amegroups. com/article/view/10.21037/shc-21-23/coif). PGS serves as an unpaid editorial board member of Shanghai Chest from June 2021 to May 2023. The other authors have no conflicts of interest to declare.

Ethical Statement: The authors are accountable for all aspects of the work in ensuring that questions related to the accuracy or integrity of any part of the work are appropriately investigated and resolved. All procedures performed in this study were in accordance with the ethical standards of the institutional and/or national research committee(s) and with the Helsinki Declaration (as revised in 2013). Written informed consent was obtained from both patients for publication of this case report and accompanying images. A copy of the written consent is available for review by the editorial office of this journal.

Open Access Statement: This is an Open Access article distributed in accordance with the Creative Commons Attribution-NonCommercial-NoDerivs 4.0 International License (CC BY-NC-ND 4.0), which permits the noncommercial replication and distribution of the article with the strict proviso that no changes or edits are made and the original work is properly cited (including links to both the formal publication through the relevant DOI and the license). See: https://creativecommons.org/licenses/by-nc-nd/4.0/.

\section{References}

1. Grillo HC, Donahue DM, Mathisen DJ, et al. Postintubation tracheal stenosis. Treatment and results. J Thorac Cardiovasc Surg 1995;109:486-92; discussion 492-3.

2. Pearson FG, Andrews MJ. Detection and management of tracheal stenosis following cuffed tube tracheostomy. Ann Thorac Surg 1971;12:359-74.

3. Stauffer JL, Olson DE, Petty TL. Complications and consequences of endotracheal intubation and tracheotomy. A prospective study of 150 critically ill adult patients. Am J Med 1981;70:65-76.

4. Díaz-Jimenez JP, Rodriguez AN. editors. Interventions in pulmonary medicine. 2nd edition. Gewerbestrasse: Springer, 2018.

5. Esteller-Moré E, Ibañez J, Matiñó E, et al. Prognostic factors in laryngotracheal injury following intubation and/or tracheotomy in ICU patients. Eur Arch Otorhinolaryngol 2005;262:880-3.

6. Papla B, Dyduch G, Frasik W, et al. Post-intubation tracheal stenosis-morphological-clinical investigations. Pol J Pathol 2003;54:261-6.

7. Sarper A, Ayten A, Eser I, et al. Tracheal stenosis aftertracheostomy or intubation: review with special regard to cause and management. Tex Heart Inst $\mathbf{J}$ 2005;32:154-8.

8. Zias N, Chroneou A, Tabba MK, et al. Post tracheostomy and post intubation tracheal stenosis: report of 31 cases and review of the literature. BMC Pulm Med 2008;8:18.

9. Stam HJ, Stucki G, Bickenbach J, et al. COVID-19 and Post Intensive Care Syndrome: A Call for Action. J Rehabil Med 2020;52:jrm00044.

10. Piazza C, Filauro M, Dikkers FG, et al. Long-term intubation and high rate of tracheostomy in COVID-19 
patients might determine an unprecedented increase of airway stenoses: a call to action from the European Laryngological Society. Eur Arch Otorhinolaryngol 2021;278:1-7.

11. Myer CM 3rd, O'Connor DM, Cotton RT. Proposed grading system for subglottic stenosis based on endotracheal tube sizes. Ann Otol Rhinol Laryngol 1994;103:319-23.

12. Cooper JD, Grillo HC. The evolution of tracheal injury due to ventilatory assistance through cuffed tubes: a pathologic study. Ann Surg 1969;169:334-48.

doi: $10.21037 /$ shc-21-23

Cite this article as: Chan EG, Hyzny EJ, Furukawa M, Luketich JD, Sanchez PG. Management of blind-end subglottic stenosis following SARS-CoV-2 infection: a case report. Shanghai Chest 2022;6:19.
13. Pearson FG, Goldberg M, da Silva AJ. Tracheal stenosis complicating tracheostomy with cuffed tubes. Clinical experience and observations from a prospective study. Arch Surg 1968;97:380-94.

14. Fiacchini G, Tricò D, Ribechini A, et al. Evaluation of the incidence and potential mechanisms of tracheal complications in patients with COVID-19. JAMA Otolaryngol Head Neck Surg 2021;147:70-6.

15. Shaukat N, Ali DM, Razzak J. Physical and mental health impacts of COVID-19 on healthcare workers: a scoping review. Int J Emerg Med 2020;13:40. 